\title{
A microtiter virus yield reduction assay for the evaluation of antiviral compounds against human cytomegalovirus and herpes simplex virus
}

\author{
Mark N. Prichard ${ }^{1,2}$, Steven R. Turk ${ }^{1}$, Lisa A. Coleman ${ }^{1}$, Sandra L. \\ Engelhardt ${ }^{1}$, Charles Shipman, Jr. ${ }^{1,2}$ and John C. Drach ${ }^{1}$ \\ Departments of ${ }^{1}$ Biologic and Materials Sciences, School of Dentistry and ${ }^{2}$ Microbiology and \\ Immunology, School of Medicine, The University of Michigan, Ann Arbor, Michigan, U.S.A.
}

(Accepted 15 December 1989)

\section{Summary}

Although the virus yield reduction assay is a powerful technique for evaluating the efficacy of antiviral compounds, it is not routinely utilized due to its labor-intensive nature. This procedure was modified, developed, thereby reducing greatly the time and effort required to perform yield reduction assays. Monolayer cultures of mammalian cells were grown in 96-well microtiter tissue culture plates and infected with virus. Test compounds were added and serially diluted directly with the plates. Following a cycle of virus replication, culture lysates were made and serially diluted in a separate set of uninfected cultures grown in microtiter plates. The cultures were incubated, plaques were enumerated in wells containing 5 to 20 plaques, and virus titers were calculated. To illustrate the use of the assay the known antiviral drugs acyclovir and ganciclovir were evaluated using this procedure. Ninety percent inhibitory concentrations for the respective drugs were $3 \mu \mathrm{M}$ and $0.7 \mu \mathrm{M}$ against herpes simplex virus type 1 and $60 \mu \mathrm{M}$ and $1 \mu \mathrm{M}$ against human cytomegalovirus.

Antiviral; Cytomegalovirus; Herpes simplex virus; Herpesvirus; Yield reduction assay

Correspondence to: S.R. Turk, Department of Biologic and Materials Sciences, School of Dentistry, The University of Michigan, Ann Arbor, MI 48109-1078, U.S.A. 


\section{Introduction}

A variety of different techniques currently are utilized in the evaluation of compounds for antiviral activity against herpesviruses. Some of the more frequently used procedures include plaque reduction (Plummer and Benyesh-Melnick, 1964; Wentworth and French, 1970), dye uptake (McLaren et al., 1983; Langlois et al., 1986), nucleic acid hybridization (Gadler, 1983; Gadler et al., 1984), and enzymelinked immunosorbent assays (Wahren et al., 1983; Rabalais et al., 1987). A less commonly used technique is the virus yield reduction assay (Shipman et al., 1976; Collins and Bauer, 1977). In this procedure virus-infected cultures are incubated with antiviral compounds for a period sufficient to permit virus replication and then assayed for the presence of new progeny virus by titration on separate monolayer cultures. Although this assay allows one to quantitate the production of infectious virions in drug-treated cultures, the labor-intensive nature of the assay thus far has precluded its widespread use as a routine technique. In an effort to simplify this assay we have modified it to take advantage of microtiter techniques. Herein we report a procedure for evaluating antiviral compounds against human cytomegalovirus (HCMV) and herpes simplex virus type 1 (HSV-1) using a microtiter virus yield reduction assay.

\section{Materials and Methods}

\section{Cells and viruses}

The routine growth and passage of primary human foreskin fibroblast (HFF) cells and an established line of African green monkey kidney (BS-C-1) cells and methods for the propagation and titration of viruses have been described previously (Turk et al., 1987). The plaque-purified $P_{0}$ isolate of the Towne strain of HCMV was a gift of Dr Mark Stinski, University of Iowa, Iowa City, IA. The S-148 strain of HSV-1 was provided by Dr Thomas Schafer of Schering Corp., Bloomfield, NJ and was subcloned in our laboratory by limiting dilution (Klein, 1975). Homogeneous virus stocks which exhibited small, uniform plaque morphology were used in this assay due to the small size of the tissue culture wells.

\section{HCMV yield reduction assay}

HFF cells were seeded into 96-well tissue culture plates at a concentration of 12500 cells per well in $0.2 \mathrm{ml}$ of minimal essential medium with Earle salts [MEM(E)] supplemented with $10 \%$ fetal bovine serum (FBS) and incubated at $37^{\circ} \mathrm{C}$ in a humidified $3 \% \mathrm{CO}_{2}-97 \%$ air atmosphere. After $24 \mathrm{~h}$ plates were inverted over a waste vessel, medium was shaken out, and the plates were allowed to drain for 5 to $10 \mathrm{~s}$ on a sterile paper towel. Cultures were inoculated with HCMV at a multiplicity of infection (MOI) of 0.5 to 1 plaque forming units (PFU) per cell in $0.2 \mathrm{ml}$ of $\mathrm{MEM}(\mathrm{E})$ supplemented with $5 \% \mathrm{FBS}, 100 \mathrm{U}$ penicillin $\mathrm{G} / \mathrm{ml}$, and 100 


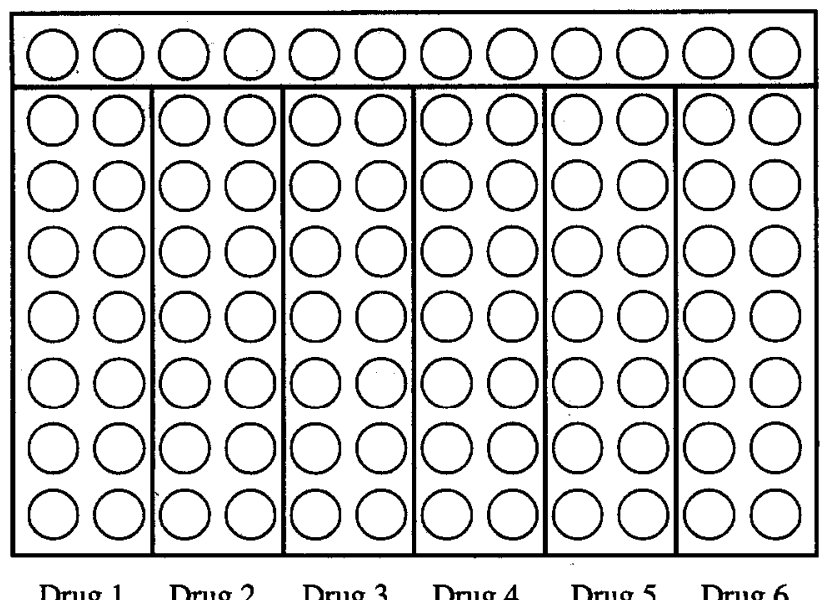

Virus Controls

$100 \mu \mathrm{M}$



$0.14 \mu \mathrm{M}$

$\begin{array}{llllll}\text { Drug } 1 & \text { Drug } 2 & \text { Drug } 3 & \text { Drug } 4 & \text { Drug } 5 & \text { Drug } 6\end{array}$

Fig. 1. Pattern of drug addition to primary culture plate in the microtiter virus yield reduction assay. Monolayer cultures of mammalian cells were infected with virus and incubated for $2 \mathrm{~h}$. Virus inoculum was removed and $0.2 \mathrm{ml}$ fresh medium was added to each well. The top row of wells served as virus controls. To each well of the second row was added $0.1 \mathrm{ml} \mathrm{of} 300 \mu \mathrm{M}$ test compound. The contents of the wells were mixed and serially diluted $1: 3$ down the plate by repeated transfer and mixing of $0.1 \mathrm{ml}$ of drug-containing solution. Final drug concentrations obtained were $100,33,11,3.7,1.2,0.41$, and $0.14 \mu \mathrm{M}$.

$\mu g$ streptomycin sulfate/ml using a microtiter multichannel pipette (Flow Laboratories, Inc., McLean, VA). Cultures were incubated at $37^{\circ} \mathrm{C}$ for $2 \mathrm{~h}$ to permit virus adsorption. Virus inoculum was replaced with $0.2 \mathrm{ml}$ of fresh medium and test compounds were added to the cultures following the pattern illustrated in Fig. 1. The first row of 12 wells was left undisturbed and served as virus controls. Each well in the second row received an additional $0.1 \mathrm{ml}$ of MEM(E) containing 5\% FBS, antibiotics, and test compound at three times the desired final concentration. The contents of the 12 wells were mixed by repeated pipetting and then serially diluted 1:3 down the plate by repeated transfer and mixing of $0.1 \mathrm{ml}$ of drug-containing medium. In this manner, six compounds could be tested in duplicate on a single plate with concentrations ranging nearly 1000 -fold between the highest and lowest dilutions $\left(0.14 \mu \mathrm{M}\right.$ to $100 \mu \mathrm{M}$, for example). Plates were incubated at $37^{\circ} \mathrm{C}$ for 7 days and then subjected to one cycle of freezing at $-76^{\circ} \mathrm{C}$ and thawing at $37^{\circ} \mathrm{C}$ to disrupt the cells. Aliquots of $0.1 \mathrm{ml}$ from each of the eight wells of a given column were transferred to the first column of a fresh 96-well monolayer culture of HFF cells. Contents were mixed and serially diluted 1:3 across the remaining 11 columns of the secondary plate. Each column of the original primary plate was diluted across a separate plate in this manner. Cultures were incubated at $37^{\circ} \mathrm{C}$ for $2 \mathrm{~h}$ to permit virus adsorption and then virus inoculum (containing residual test compounds carried over from the primary plate) was replaced with $0.2 \mathrm{ml}$ of fresh medium. Cultures were incubated for 7 days, medium was removed, and the cell sheets were stained with $0.1 \%$ crystal violet in $20 \%$ methanol. Plaques were 
enumerated under 20-fold magnification in the column of wells having the dilution which gave 5 to 20 plaques per well. Virus titers were calculated according to the following formula: Titer $(\mathrm{PFU} / \mathrm{ml})=$ number of plaques $\times 5 \times 3^{n}$; where $n$ represents the $n^{\text {th }}$ dilution of the virus used to infect the well in which plaques were enumerated.

\section{HSV-1 yield reduction assay}

The procedure was essentially the same as for HCMV with the following modifications: (i) BS-C-1 cells were used in place of HFF cells and were seeded at a concentration of 10000 cells per well in MEM(E) containing calf serum instead of FBS, (ii) cultures were inoculated with HSV-1 at an MOI of five PFU per cell, (iii) the primary drug-treated cultures were incubated overnight rather than for 7 days, and (iv) secondary cultures were incubated for 2 days before staining.

\section{Results and Discussion}

The virus yield reduction assay is a powerful technique for evaluating the efficacy of potential antiviral compounds. It is a more stringent measure of the process of virus infection and drug activity than the plaque reduction assay because the MOI is usually one or more PFU per cell as opposed to less than 0.01 PFU per cell in plaque reduction assays. In addition, the use of a higher MOI and the quantitation of progeny virus permits the determination of antiviral activity over a much greater range $\left(1-10^{6} \mathrm{PFU} / \mathrm{ml}\right.$ in yield reduction compared to $1-10^{2} \mathrm{PFU}$ in plaque reduction), thereby permitting the measurement of more profound drug effects. The capacity of drugs to produce multiple 10 -fold reductions in virus titer in vitro appears to correlate with in vivo drug efficacy. Despite these advantages, the virus yield reduction assay is not routinely utilized by many investigators due to its labor-intensive nature.

In commonly reported versions of this assay (Cheng et al., 1983; Rasmussen et al., 1984; Turk et al., 1987; Snoeck et al., 1988) the primary drug-treated cultures are grown in $25 \mathrm{~cm}^{2}$ flasks, petri dishes, or 24-well tissue culture plates. Culture lysates are prepared, diluted in test tubes, and virus titrated in 6-, 24-, or 96-well plates. The use of microtiter techniques throughout the entire assay as reported herein simplifies this assay in a variety of ways, greatly reducing the handling required. Six compounds can be assayed in duplicate using a total of only thirteen 96-well culture plates. Test compounds are quickly and easily diluted directly in the wells of the plates. Similarly, culture lysates are diluted directly in the secondary culture plates. Utilization of 1:3 dilutions across a 12-well row is sufficient to permit quantitation of up to $10^{6} \mathrm{PFU}$ of virus per ml of a given cell lysate. In experiments in which higher virus titers are obtained, serial dilutions of the culture lysates may be extended across a portion of a second 96-well plate. In contrast to procedures using culture plates with larger wells, no solid or semi-solid overlay medium for the prevention of secondary plaques has proven necessary when using 

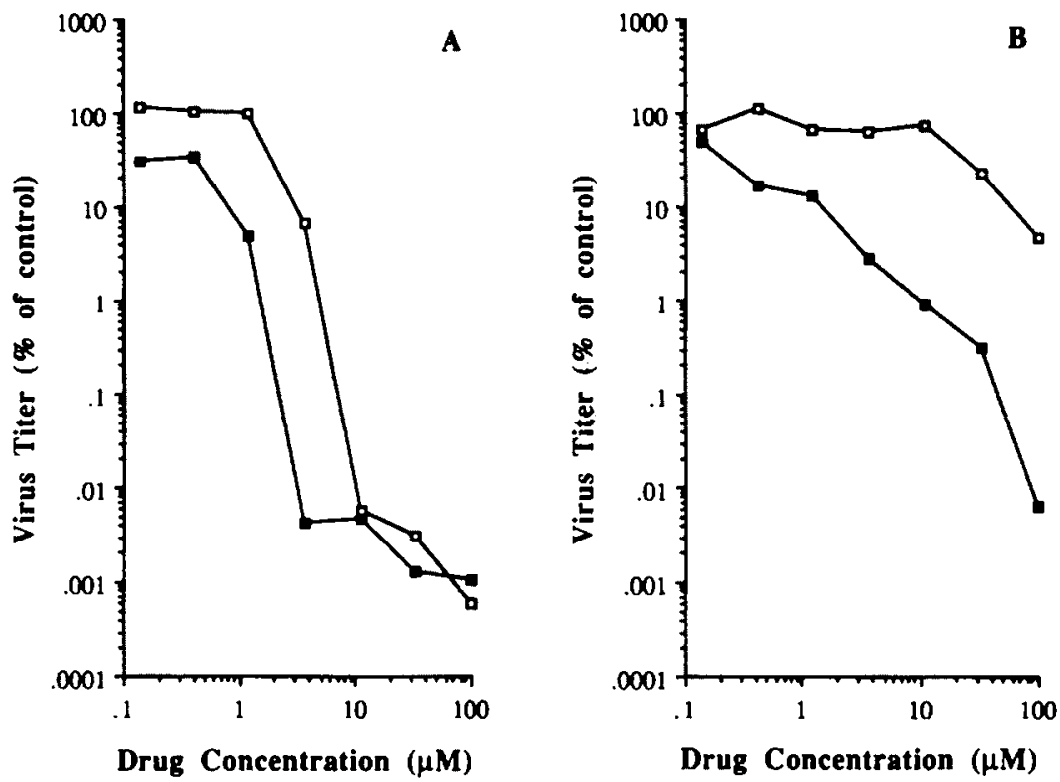

Fig. 2. Antiviral effect of acyclovir ( $(\square)$ and ganciclovir ( $(\boldsymbol{)})$ on the replication of HSV-1 (panel A) and HCMV (panel B) in the microtiter virus yield reduction assay. Each point represents the average of duplicate determinations. Control virus titers for HSV-1 and HCMV wete $6.3 \times 10^{6}$ and $1.3 \times 10^{6}$ plaque forming units per $\mathrm{ml}$, respectively.

microtiter plates. Lastly, the endpoint wells in which plaques' are enumerated typically contain fewer than 20 plaques, greatly simplifying this counting step.

To illustrate the utility of the microtiter yield reduction assay we examined the antiviral activity of acyclovir (Burroughs Wellcome Co., Research Triangle Park, NC) and ganciclovir (Syntex, Palo Alto, CA) against both HSV-1 and HCMV. As illustrated in Fig. 2A, both compounds possess potent antiviral activity against HSV1. Virus titers were reduced nearly $10^{5}$-fold in cultures treated with $100 \mu \mathrm{M}$ of either compound. Ninety percent inhibitory concentrations of $0.7 \mu \mathrm{M}$ and $3 \mu \mathrm{M}$ can be interpolated from the dose-response curves for ganciclovir and acyclovir, respectively. Fig. 2B reveals that ganciclovir is a potent inhibitor of HCMV replication $\left(>10^{4}\right.$-fold reduction in virus titer at $\left.100 \mu \mathrm{M}\right)$ whereas acyclovir is 1000 -fold less active. Ninety percent inhibitory concentrations for the respective compounds are $1 \mu \mathrm{M}$ and $60 \mu \mathrm{M}$. These results using the microtiter assay compare favorably with results reported by other investigators using their versions of the virus yield reduction assay (Cheng et al., 1983; Rasmussen et al., 1984). In contrast, plaque reduction assays for the two drugs do not adequately demonstrate their significant difference in activity against HCMV. For example, we have found in multiple experiments that the difference between 50 percent inhibitory concentrations for the two compounds was only 7-to 8-fold (ganciclovir $=8.8 \mu \mathrm{M}$, acyclovir $=63 \mu \mathrm{M}$ ) (Pudlo et al., 1988), not 60 - to 1000 -fold as revealed by yield reduction assay.

In conclusion, we believe the virus yield reduction assay to be a more powerful and predictive technique than is the plaque reduction assay. Utilization of micro- 
titer techniques has the benefit of reducing the time and amount of materials required to perform the assay thereby providing a feasible method to routinely derive more meaningful results in the evaluation of antiviral compounds.

\section{Acknowledgements}

This work was supported with federal funds from the Department of Health and Human Services under contracts AI-42554 and AI-72641 and by Public Health Service grant DE 09066 from the National Institute of Dental Research.

\section{References}

Cheng, Y.-C., Huang, E.-S., Lin, J.-C., Mar, E.-C., Pagano, J.S., Dutschman, G.E. and Grill, S.P. (1983) Unique spectrum of activity of 9-[(1,3-dihydroxy-2-propoxy)methyl]guanine against herpesvirus in vitro and its mode of action against herpes simplex virus type 1. Proc. Natl. Acad. Sci. USA $80,2767-2770$.

Collins, P. and Bauer, D.J. (1977) Relative potencies of anti-herpes compounds. Ann. N.Y. Acad. Sci. $284,49-59$.

Gadler, H. (1983) Nucleic acid hybridization for measurement of effects of antiviral compounds on human cytomegalovirus DNA replication. Antimicrob. Agents Chemother. 24, 370-374.

Gadler, H., Larsson, A. and Sølver, E. (1984) Nucleic acid hybridization, a method to determine effects of antiviral compounds on herpes simplex virus type 1 DNA synthesis. Antiviral Res. 4, 63-70.

Klein, R.J. (1975) Isolation of herpes simplex virus clones and drug resistant mutants in microcultures. Arch. Virol. 49, 73-80.

Langlois, M., Allard, J.P., Nugier, F. and Aymard, M. (1986) A rapid and automated colorimetric assay for evaluating the sensitivity of herpes simplex strains to antiviral drugs. J. Biol. Stand. 14, 201-211.

McLaren, C., Ellis, M.N. and Hunter, G.A. (1983) A colorimetric assay for the measurement of the sensitivity of herpes simplex viruses to antiviral agents. Antiviral Res. 3, 223-234.

Plummer, G. and Benyesh-Melnick, M. (1964) A plaque reduction neutralization test for human cytomegalovirus. Proc. Soc. Exp. Biol. Med. 117, 145-150.

Pudlo, J.S., Saxena, N.K., Nassiri, M.R., Turk, S.R., Drach, J.C. and Townsend, L.B. (1988) Synthesis and antiviral activity of certain 4- and 4,5-disubstituted 7-[(2-hydroxyethoxy)methyl]pyrrolo[2,3-d]pyrimidines. J. Med. Chem. 31, 2086-2092.

Rabalais, G.P., Levin, M.J. and Berkowitz, F.E. (1987) Rapid herpes simplex virus susceptibility testing using an enzyme-linked immunosorbent assay performed in situ on fixed virus-infected monolayers. Antimicrob. Agents Chemother. 31, 946-948.

Rasmussen, L., Chen, P.T., Mullenax, J.G. and Merigan, T.C. (1984) Inhibition of human cytomegalovirus replication by 9-(1,3-dihydroxy-2-propoxymethyl)guanine alone and in combination with human interferons. Antimicrob. Agents Chemother. 26, 441-445.

Shipman, C., Jr., Smith, S.H., Carlson, R.H. and Drach, J.C. (1976) Antiviral activity of arabinosyladenine and arabinosylhypoxanthine in herpes simplex virus-infected KB cells: Selective inhibition of viral deoxyribonucleic acid synthesis in synchronized suspension cultures. Antimicrob. Agents Chemother. 9, 120-127.

Snoeck, R., Sakuma, T., De Clercq, E., Rosenberg, I. and Holy, A. (1988) (S)-1-(3-hydroxy-2-phosphonylmethoxypropyl)cytosine, a potent and selective inhibitor of human cytomegalovirus replication. Antimicrob. Agents Chemother. 32, 1839-1844.

Turk, S.R., Shipman, C., Jr., Nassiri, R., Genzlinger, G., Krawczyk, S.H., Townsend, L.B. and Drach, J.C. (1987) Pyrrolo[2,3-d]pyrimidine nucleosides as inhibitors of human cytomegalovirus. Antimicrob. Agents Chemother. 31, 544-550.

Wahren; B. et al. (1983) A novel method for determining the sensitivity of herpes simplex virus to antiviral compounds. J. Virol. Methods 6, 141-149.

Wentworth, B.B. and French, L. (1970) Plaque assay of cytomegalovirus strains of human origin. Proc. Soc. Exp. Biol. Med. 135, 253-258. 